\title{
LLUSCUMA DE JORGE BARADIT: CIENCIA FICCIÓN Y LAS CUENTAS DEL PASADO ${ }^{1}$
}

\author{
Lluscuma de Jorge Baradit: \\ Science fiction and unfinished business of the past
}

Cristian Montes*

\begin{abstract}
RESUMEN
La novela Lluscuma de Jorge Baradit, inserta en el género de la ciencia ficción, desarrolla, a partir del conjunto de hechos narrados y del discurso de idea desplegado, una revitalización del tema de la memoria y una reflexión respecto a lo acaecido en tiempos de la dictadura militar chilena y sus consecuencias en el tejido social del país. La necesidad de una justicia que ha tardado demasiado en concretarse y el pacto de silencio que reina en torno a los detenidos desaparecidos son aspectos que la novela desarrolla, en función de subrayar la necesidad de seguir realizando un duelo activo a nivel de país y de rechazar la impunidad de los responsables de las atrocidades cometidas.
\end{abstract}

Palabras clave: ciencia ficción, dictadura, detenidos desaparecidos, memoria, justicia.

\footnotetext{
${ }^{1}$ El presente artículo se inserta en el proyecto Fondecyt Número 1151484: "La narrativa de los hijos de la dictadura: sustrato apocalíptico e interminable proceso de duelo", del cual soy investigador responsable.

* Facultad de Filosofía y Humanidades, Departamento de Literatura, Universidad de Chile. Santiago, Chile. Correo electrónico: cmontes@vtr.net

Artículo recibido el 12 de marzo de 2018. Aceptado el 21 de junio de 2018.
} 


\begin{abstract}
The novel Lluscuma, by Jorge Baradit, inserted in the genre of science fiction, develops from a set of narrated events and the discourse on the revitalization of the subject of memory and a reflection upon that which took place during Chile's military dictatorship and its consequences on the country's social fabric. The novel explores aspects of the need for a justice that has taken too long to transpire and the pact of silence that reigns around the detained and disappeared as a means of underscoring the need to continue an active mourning at the national level and reject the impunity of those responsible for the atrocities committed.
\end{abstract}

Keywords: science fiction, dictatorship, detained and disappeared, memory, justice.

\title{
1. Introducción
}

El género de la ciencia ficción, tanto en el ámbito de la literatura como del cine, ha sido una vía privilegiada no solo para imaginar el futuro, sino también para repensar la historia y denunciar las lacras y peligros del presente ${ }^{2}$. Es imprescindible por ello, dado que el diálogo con la realidad histórica y con el presente es inevitable, "considerar la relación entre el mundo construido por la Ciencia Ficción y el del momento histórico en el que se crea y se lee" (Córdoba 104). Como señala Cristina Sánchez, las interrogantes acerca del pasado, el presente y el futuro que los textos de ciencia ficción actualizan, poseen similitudes que, a pesar de la distancia del lugar de enunciación, expresan un conflicto existencial compartido. Los escritores coinciden en el hecho de estar:

presentando cuestiones universales sobre la humanidad, tales como 1) ¿qué es ser humano hoy y hasta qué punto se puede considerar a los humanos seres racionales?; ¿qué tipos de guerras son las que se llevan a cabo hoy y cuáles son las causas de esas guerras?; 3) ¿cómo se manifiesta en la sociedad los conflictos derivados del

\footnotetext{
${ }^{2} \mathrm{Al}$ referirse a las complejas relaciones que se establece entre el género de la ciencia ficción y el pasado, Gabriel Trujillo afirma que: "la ciencia ficción ha utilizado la historia como un recurso narrativo. La historia, debido a esto, se divide en un pasado reinventado y en un futuro controlado. El pasado reinventado tiene como mejor ejemplo las aventuras llamadas de "espada y brujería", que tienen lugar en tiempos de héroes de fuerza legendaria. En este caso, el paradigma es Conan, el cimerio, creación del escritor Robert Ervin Howard (1906-1936) (...) En cuanto a la otra vertiente de la ciencia ficción: el futuro controlado, el ciclo de novelas de Isaac Asimov, titulado Fundación, es el mejor ejemplo" (286-287).
} 
nacionalismo, el racismo y el feminismo?; 4) ¿qué es la Historia y cómo está siendo interpretada hoy por los escritores y cineastas de ciencia ficción (...)?; 5) ¿son la ciencia, la religión discursos complementarios o antagónicos en el conocimiento de las realidades humanas?; 6) ¿qué implican los avances tecnológicos para el futuro de la humanidad? (Cristina Sánchez 6-7).

Tales inquietudes, por supuesto, no son privativas del discurso de la ciencia ficción, sino parte de un conjunto de preocupaciones vitales del sujeto contemporáneo. Como ocurre con otras materialidades discursivas, el género funda su eficacia expresiva en la capacidad de extrañamiento ante lo dado a la percepción:

El género de la ciencia ficción es precisamente una colección de discursos que no son necesariamente ni excluyentes con respecto a otras modalidades de escritura y que se despliegan para realizar lo que Sklovski considera la función fundamental del arte, la producción de ostranenie. Ostranenie es el proceso o acto que extrae a un objeto de la red de percepciones automatizadas y expresiones lingüísticas convencionales (Córdoba 68).

Las condiciones y focalizaciones del extrañamiento en el acto de la recepción varían según sean los acontecimientos narrados y la contextualización epocal de éstos. En Latinoamérica las peculiaridades del género han ido enriqueciéndose a partir de la reflexión y obra de escritores como Jorge Luis Borges, Adolfo Bioy Casares, Santiago Dabove, entre otros autores que permiten establecer una determinada genealogía, especialmente en relación con el concepto de lo fantástico ${ }^{3}$. En dicho proceso se advierte un predominio, hasta la década del 2000, de una tendencia donde el futuro se configura y presenta como una continuación lógica y casi automática de fenómenos identificables en el presente. Se trata de contrautopías situadas en un futuro cercano, como puede observarse en novela tales como Angosta (2004) de Abad Faciliolinci, El oído absoluto (1989) de Marcelo Cohen o Waslala (1996) de Gioconda Belli. Son obras que emplean el futuro como

\footnotetext{
${ }^{3}$ Por ello se entiende, en términos de Tzvetan Todorov, un género evanescente de muy difícil precisión, pero que puede determinarse en relación a dos categorías: lo maravilloso y lo extraño. Lo sustantivo de su mecanismo operatorio y la primera condición de lo fantástico es "la vacilación experimentada por un ser que no conoce más que las leyes naturales, frente a un acontecimiento aparentemente sobrenatural" (34).
} 
metáfora y se comportan como una reacción metafísica con el presente, activando por ello, a la vez, una dimensión alegórica (Córdoba 103-115).

En lo que respecta a Chile, Macarena Areco revisa la producción narrativa de ciencia ficción chilena, desde sus orígenes hasta los primeros años del siglo XXI. Según afirma la estudiosa, respecto a la etapa de Fundación, ésta puede remontarse a 1878, año en que se publica la novela Desde Júpiter de Francisco Miralles ${ }^{4}$. Luego viene la etapa del Preludio, de 1900 a 1959, donde se observa una preeminencia de explicaciones maravillosas por sobre las científicas, como ocurre en la novela En la ciudad de los Césares (1939) de Enrique Délano, posteriormente una "Edad de oro" que va de 1959 a 1975, con novelas como Los superhomos (1963) de Antonio Montero, luego una etapa de notorio decaimiento en los primeros tiempos de la dictadura militar y un tímido repunte en los años 80 , con la publicación de La última canción de Manuel Sendero (1982) de Ariel Dorfman y El ruido del tiempo (1987) de Claudio Jaque, entre otras novelas donde predomina la contingencia política chilena ("Visión del porvenir y espejo del presente" 116-127).

Será en los años 90, una vez alcanzada la democracia, que se generará verdaderamente la recuperación del género. Producciones narrativas como Flores para un cyborg (1997), de Diego Muñoz Valenzuela, 2020: Chile en llamas (1998) de Darío Oses, entre otras novelas y autores, son prueba fehaciente de ello. En cuanto a la narrativa de estos últimos años, Areco afirma que: "La ciencia ficción chilena se manifiesta en los inicios del siglo XXI acaso con más fuerza que nunca, pues los nuevos formatos que ha ido incorporando y las hibridaciones en que ha ido contagiándose de otros géneros, le han permitido potenciar su capacidad de espejar el presente a través de sus imaginaciones del futuro" ("Visión del porvenir y espejo del presente" 131). El resurgimiento del género se enriquecerá en estas primeras décadas del 2000 con novelas como Identidad suspendida (2006) de Sergio Almira, Los tiempos de la caimaguana (2011) de Dauno Tótoro, Ygdrasil (2005) de Jorge Baradit,

\footnotetext{
${ }^{4}$ Macarena Areco agrega que Marcelo Novoa y Omar Vega, en el libro Años Luz (2006), plantean que existiría una obra anterior, de 1875, titulada ¡Una visión del porvenir! O el espejo del mundo de Benjamin Tallman, cuyo autor sería David Tillman y de la cual no se han encontrado ejemplares ("Visión del porvenir y espejo del presente" 117).
} 
la selección preparada por Marcelo Novoa: Años Luz. Mapa estelar de la ciencia ficción en Chile (2006), La segunda enciclopedia de Tlön (2007) de Sergio Meier, las colecciones de relatos Alucinaciones.txt y Poliedro (2007) y El Púgil (2008) de Mike Wilson, entre otras novelas ("Visión del porvenir como espejo del presente" 46).

Dentro de este ingente corpus de producciones narrativas se destaca la obra de Jorge Baradit. La intención de estas páginas será concentrarse en su novela Lluscuma (2013), específicamente en las relaciones que se establecen entre el género de la ciencia ficción y un discurso narrativo en el que se revitaliza la importancia de la memoria y se denuncia lo sucedido en tiempos de dictadura, especialmente lo que fueron los crímenes y desaparición de miles de personas. Con estrechos vínculos con los géneros de lo fantástico y del horror y con la novela de fantasía, el discurso de la ciencia ficción en Lluscuma deviene vía privilegiada para la revitalizar creativamente los procesos de memoria y dispositivo crítico a través del cual dialogar con el presente.

\section{De pampa Lluscuma a la ficcionalización de la historia}

El genotexto de la novela Lluscuma (2013), entendiendo por dicho concepto un dispositivo o impulso desde el cual surge un determinado texto, antes de ser procesado en la ficción (Jitrik 65), fue la supuesta abducción extraterrestre de la que fue objeto el cabo del ejército chileno, Armando Valdés, el 25 de abril de 1977, uno de los años más violentos y represivos de la dictadura militar chilena. Este episodio de la historia nacional, de claros tintes sensacionalistas y de dudosa veracidad, activa en la novela de Baradit una trama novelesca que tiene en el narrador personaje, Fernando Camargo, el centro principal de la atención narrativa. Particular énfasis se coloca en el accidente que este sufrió cuando niño, debido a una brutal golpiza de su padre, lo que produjo en su cerebro la ruptura del parietal derecho y con ello los intensos y continuos dolores de cabeza que sufre. A esto debe agregarse que su abuelo, exoficial del ejército, fue un torturador al servicio de la dictadura e integrante de la Caravana de la Muerte, situación que le genera a Fernando Camargo un 
acuciante sentimiento de culpa. Cuando su abuelo fallece, descubrirá que éste ocultaba debajo de su cama un arma y una cinta etiquetada como: "Lluscuma 25 de abril de 1977, video de propiedad del Ejército de Chile, Alto Secreto Militar" (29), donde se explica en qué consiste dicho proyecto y cuál era la verdadera intención de los experimentos realizados en la pampa nortina. Se constata así que no fue realmente un problema de abducción lo que había experimentado el cabo Armando Valdés, sino la puesta en acción de un mega proyecto que intentaba abrir una grieta en el espacio, para enviar hacia otro nivel de realidad a presos políticos de la dictadura ${ }^{5}$. A partir del "aullido" producido por una frecuencia de sonido que el video del abuelo registró, sería posible utilizar los cuerpos de los desaparecidos como fundas para que los "oscuros" de "arriba", como los llama el narrador, pudieran ingresar a la realidad terrena, "para así emerger por la antena como el despertar violento de un país hecho cyborg, encarnado, recibiendo la transmisión incesante de almas convertidas en pulsos de datos, el clamor de millones que saldrían desde la piel de nuestra mente (...) Para eso necesitaban cuerpos llenos de ímpetu, carne fogosa para sus trajes de astronauta" (195). Finalmente, el proyecto Lluscuma fracasa y el cabo Armando Valdés regresa desde los cielos, demacrado y con una barba de 5 días, mientras en la tierra no han transcurridos más de 15 minutos.

Este suceso será el epicentro narrativo desde el cual se irán adicionando diversos acontecimientos de la historia de Chile. A partir de una conciencia en estado de exaltación paranoica, proclive a la constante disociación de la realidad, se desplegará un discurso febril, en donde lo que ve y cuenta el narrador puede interpretarse como la proyección de una mente distorsionada que no logra diferenciar entre lo que está ante sus ojos y los contenidos que su mente genera ${ }^{6}$.

Lo que comúnmente se definiría como un relato de ciencia ficción,

\footnotetext{
${ }^{5}$ Esta información, a manera de un leitmotiv, es reiterada en diversos momentos del texto. A modo de ejemplo, el siguiente enunciado es particularmente elocuente: "El tipo lo interrumpe para reconocer que usaban detenidos políticos para aquello grande que se planeaba en Lluscuma, para el bien de la patria" (128).

${ }^{6}$ Algunos segmentos donde puede apreciarse el estado psíquico distorsionado del narrador personaje, son: "(..) creo escuchar los pensamientos de todos" (31), "La calle es una ametralladora" (31"), "Una hormiga me muerde un nervio y siento un clavo entrándome por
} 
se funde aquí con la trama alucinada de una mente desligada del orden de la realidad, debido al daño producido en el cerebro del narrador personaje, al trauma de tener un abuelo torturador y por todo lo sucedido en Chile, especialmente en tiempos de dictadura. El sentimiento de culpa por lo cometido por su abuelo y todo lo que éste representa, generan en la mente del personaje la necesidad de venganza y de justicia. Comenzará a martirizarlo en su cama de moribundo, detallándole los aspectos más escabrosos de los asesinatos y torturas denunciados por el informe Rettig: "Me sentía impartiendo justicia leyéndole sus atrocidades, pero solo me estaba vengando. Ni siquiera por las víctimas, sino por haberme cagado la infancia, por la decepción" (176).

El conjunto de síntomas que el personaje sufre incide en la configuración de un tipo de delirio que parece funcionar como un muro de contención ante la realidad que atormenta su subjetividad alterada, como una manera de conciliar los recuerdos dolorosos de la memoria nacional. El delirio y la paranoia se ligan al tema del trauma en la creación de una escena donde el personaje piensa que en Chile se vive una guerra y que ésta posee desconocidas ramificaciones y variantes, siendo la principal una confrontación que percibe al interior del ejercicio de la memoria colectiva y que es la responsable de la desintegración de la realidad: "A veces pienso que hay alguien peleando una guerra contra la memoria" (32). Ello incide en la puesta en duda del personaje respecto a su propia identidad y la de quienes supuestamente lo están cercando.

Es importante destacar que la compleja sintomatología que adolece el narrador personaje no inhibe ni deslegitima su discurso, en cuanto a la capacidad de éste de crear un mundo fictivo regulado por sus propias leyes. Teniendo este factor en cuenta, puede afirmarse que Lluscuma no es una novela ejemplarmente representativa del género de ciencia ficción clásico, ya que la fantasía y la imaginación desplegada no afirman un determinado tipo

el oído derecho" (46), "Todo lo estoy soñando, no crean que estoy loco (...) Veo Santiago desde la altura porque ahora soy un gigante hecho de lava y hueso astillado (...). Soy el magma que los chilenos tenemos en vez de sangre" (51), "Hay alguien soldándome al arco los parietales, chuteando un córner con mi cabeza" (68), "Quiero pensar normalmente y dejar de nadar viendo tanta huevada donde no las hay, tata, por favor." (73), "Mi papá no está muerto, Sole, está en la Luna, se lo llevaron los gringos para sus viajes secretos a nuestro satélite, vi una insignia del Apolo XXIV en una foto que bajamos de internet (71).” 
de saber racional sobre la ciencia y la tecnología. Tampoco se observa que en el proceso de enunciación la búsqueda de conocimiento devenga motivación narrativa. Darko Suvin postula que en dicho género literario el extrañamiento y la cognición son condiciones tanto necesarias como suficientes. Constituyen el motor principal narrativo, en el sentido de que lo extraño, que en otros contextos como lo fantástico o el terror permanece inexplicado, encuentra una verosimilización en el modo que una cultura imagina el trabajo científico, los modos de producción de tecnología, de bienes y de subjetividades (30)7. A pesar de que en la actualidad los estudios sobre ciencia ficción ya no consideran que el género requiera ser un difusor del conocimiento científico y que deba poseer cualidades predictivas, la ciencia continúa siendo absolutamente relevante, puesto que, sin su presencia, es decir sin premisas y un marco científico, el género tiene a desnaturalizarse (Merril 60) ${ }^{8}$.

\section{Ciencia ficción y memoria crítica: una renovada apertura del género}

Cabe recalcar que en el caso de Lluscuma, esta condición acerca del saber asignado al género es obliterada en gran medida debido a la preeminencia de otros cauces temáticos, como la violencia generalizada o la destrucción apocalíptica, lo que coincide con la percepción de Susan Sontag de que muchos relatos de ciencia ficción no versan realmente sobre ciencia ficción, sino sobre desastres que advierten acerca de lo que podría ocurrir si determinadas cosas

\footnotetext{
${ }^{7}$ Diversos expertos en el tema señalan que el discurso de la ciencia ficción posee siempre una base racional y lógica y una causalidad específica. Al respecto, Stanislav Lem plantea que la premisa fundamental de la ciencia ficción es que cualquier cosa que se muestra ha de ser, por principio, interpretable desde un punto de vista empírico y racional. En la ciencia ficción no puede haber maravillas que sean inexplicables, puesto que los acontecimientos han de ser plenamente verosímiles (35).

${ }^{8}$ Judith Merril señala que : "Speculative fictions: stories whose objectives is to explore, to discover, to learn, by means of projection, extrapolation, analogue, hypothesis -and -paperexperimentation, something about the nature of the universe, of man, of reality (...) Y use the term "speculative fiction" here specifically to describe the mode which makes use of the traditional "scientific methods" (observation, hypothesis, experiment) to examine some postulated approximation of reality, by introducing a given set of changes -imaginary or inventive into the common background of "known facts", creating and environment in which the responses and perceptions of the characters will reveal something about the inventions, the characters or both" $(60)$.
} 
continuasen en la misma dirección (128) 9 .

En Lluscuma la pregunta por el saber se transforma en una suspicaz interrogante acerca de la existencia y productividad del mismo. El discurso constructivo de la ciencia ficción no funciona tanto como una matriz estructurante, sino como una especie de decorado para la catástrofe generalizada que el texto denuncia. Más que el eje del saber, el principal foco de atención en Lluscuma es la historia de Chile. El material narrativo privilegia, en consecuencia, más el pasado que un futuro imaginado; más la memoria y los acontecimientos que continúan incidiendo en el año 2013.

El formato de la ciencia ficción opera en Lluscuma como el género mayor de un discurso que denuncia lo sucedido en tiempos de dictadura, es decir los crímenes, las torturas y especialmente la desaparición de personas. El trabajo de memoria realizado, junto a trasmitir la experiencia de la extrema violencia vivida en esos años, evidencia, al mismo tiempo, el deseo de solidaridad y respeto por las víctimas, lo que revela una postura ética que Carlos Pabón define como el "momento ético", es decir "el deber de la memoria (que) se da respecto a las víctimas que han sido desaparecidas, aniquiladas, a los sin nombre, a los silenciados" (20). El tema de los detenidos desaparecidos se expone en Lluscuma como un mecanismo codificado y un método de tortura que a pesar de borrar las marcas físicas dejó una huella psíquica indeleble en el colectivo social. Tal como señala Antonia García, la desaparición "no sólo elimina, no sólo sustrae cuerpos, la desaparición busca penetrar imaginarios mediante los cuales se extiende el campo de intervención de ese poder que quiere ser absoluto mucho más allá de los límites de los centros clandestinos, de las cárceles, de los campos de concentración" (89).

En esta misma línea, Jean Franco, enfatizando no solo la crueldad de las estrategias y medios utilizados para la desaparición de personas, sino también el engaño y la mentira, postula que:

\footnotetext{
${ }^{9} \mathrm{Al}$ analizar diversos films de ciencia ficción de los años 50 y 60, Sontag afirma que estos carecen de crítica social y no generan una reflexión sobre los riesgos de la deshumanización del ser humano a partir de la ciencia y la tecnología, o de los diversos miedos que sufre la sociedad actual: "There is absolutely no social criticism, of even the most implicit kind in science fiction film" (128).
} 
La transparencia no era una opción para los regímenes militares. Era necesario ocultar los asesinatos para evitar la atención internacional, razón por la cual se montaron elaborados engaños. En este espantoso teatro, los cuerpos de las víctimas ejecutadas en ocasiones se mostraban como si hubieran muerto en una batalla con las fuerzas armadas. Muchos de los desaparecidos fueron ejecutados o aventados desde aviones mientras estaban drogados (266).

Lluscuma indaga justamente en esos ámbitos donde la experiencia del terror dejó sus huellas y demuestra que los crímenes y desapariciones no son patrimonio del pasado, sino una realidad que presiona y signa al presente con rasgos escatológicos y tanáticos. Podrá haberse hecho desaparecer un cuerpo, pero, como dice el narrador: "el muerto desaparecido rasca el suelo bajo nuestra casa" (183).

Por otro lado, la novela de Baradit relativiza la univocidad del discurso oficial y el sospechoso criterio selectivo de lo que se cuenta o no de la historia de Chile. Memoria y olvido son los términos que en una tensión constante regulan el verosímil de un país que se configura en clave de delirio y alucinación. Puede entreverse una visión de la historia marcada por una sensación de derrota, lo que desemboca en una percepción fragmentaria e inabarcable del presente. En coincidencia con un diagnóstico de este tipo, Nelly Richard considera que: "Ni la cruel historia oficial de los dominadores ni la dolorosa historia contra oficial de los dominados eran ya capaces de orientar el sujeto cultural hacia una finalidad y coherencia de sentido y de interpretación" (26).

Esta dificultad generalizada de alcanzar un discurso aglutinador de las urgencias sociales y colectivas se articula en Lluscuma a una concepción circular de la historia, la que "no sabe sino repetirse a sí misma" (183) y a una concepción del pasado como una materia que está "reescribiéndose y regrabándose constantemente en nuestras memorias" (223) y donde siempre retorna aquello que avergüenza al país: "En el norte se levantaron los obreros del cobre y desde Chuquicamata amenazan con avanzar sobre Santiago con pelotones de fantasmas de soldados de la guerra del pacífico y anarquistas fusilados que volvieron de los paredones" (203). Se evidencia así, como afirma Daniel Noemi, que "El pasado no pasa. La violencia tampoco" (130). Por tal 
razón "la literatura de la violencia deviene literatura de la memoria y, como tal, literatura del presente que puede servirnos para descubrir y revelar" (139).

El retorno de hechos violentos de la historia de Chile forma parte de una dinámica de reactualización y resignificación del pasado, a través de constantes repeticiones y desajustes que dislocan la supuesta objetividad de los sucesos descritos. Se refuerza la idea de que por debajo del relato hegemónico existen siempre diferentes perspectivas y variantes interpretativas de la realidad. Como señala Baradit en una entrevista: "En un país donde la historia oficial ha estado constantemente construida a conveniencia de un sector pequeño de la población, que cuenta las cosas a su modo, filtrada por sus intereses (...) obviamente las incongruencias del "guión" se prestan para recontar y buscar la "verdadera verdad". O, derechamente, ante la imposibilidad de conciliación, inventarse la propia y punto. Me interesa la memoria, pero a la manera de los rostros de Roger Bacon o la imaginería de Matta, deformes como un sueño"10.

En Lluscuma los acontecimientos traumáticos del pasado son convocados de manera simultánea en un presente que interpreta, indaga, transforma y reconstruye dichos contenidos de memoria con mirada polivalente. Por su parte, el pasado reconfigurado por la imaginación narrativa moldea el presente de la narración y la subjetividad inscrita en el proceso de enunciación. En este cruce e interferencia de espacios y coordenadas temporales no sorprende la presencia de cadáveres de la Guerra del Pacífico emergiendo del desierto y preguntando por sus tropas, o que un soldado boliviano y combatiente de la misma guerra se confronte con uno de los escoltas de Pinochet que murieron en el atentado en el que se intentó asesinarlo, o que se genere un nuevo levantamiento de la Wallmapu en la Araucanía, o que resurjan brujos y magos chilotes apoyando la resistencia española en contra de la Independencia, o que una niña prediga en 1891 el advenimiento de almas atrapadas en el otro mundo y que reaparecerán en pampa Lluscuma en 1977, o que el país esté sufriendo un conjunto de sucesos anormales como bombas que explotan en el presente, pero que fueron implantadas en el pasado, o que

${ }^{10}$ Citado por Jonathan Castro en El Sismógrafo Webzine/Revista. Cultura y Política. Junio 19 de 2016. 
la Moneda sea absolutamente destruida, entre otros acontecimientos de sesgo apocalíptico y distópico.

\section{Sustrato apocalíptico / revitalización de lo (casi) perdido}

La dimensión apocalíptica presente en la representación de mundo permite insertar la novela en un determinado corpus latinoamericano donde se observan coincidencias temáticas y formales. Según Geneviève Fabry e Ilse Logie, en textos como los de Bolaño, Liscano y Coheno Mairal, puede apreciarse "que éstos contienen (...) las dos búsquedas paralelas que Parkinson Zamora considera constantes en el registro apocalíptico: la de un entendimiento de su contexto histórico, y la de los medios de narrar ese entendimiento. El apocalipsis es, en términos generales, un modo de aludir a otros problemas; de allí que las novelas (pos) catástrofe tiendan a subvertir el pacto mimético y a plantear la ficción como un lugar desde donde alegorizar el presente (17)". En este sentido, y ligando lo dicho al discurso de la ciencia ficción, puede afirmarse que éste "no nos entrega imágenes del futuro (...) sino que más bien desfamiliariza y reestructura nuestra experiencia del presente" (Jameson 151).

En la novela de Baradit la atmósfera apocalíptica y el desastre generalizado son el marco a partir del cual se inaugura la diégesis y el punto de hablada de la narración: "Hoy es 26 de mayo de 2012 y mi país se desmorona, como se desmorona el cielo sobre mi territorio que se remueve y tiembla bajo nuestros pies cada vez que tiene malos sueños" (11). La guerra generalizada que tiene al país en ruinas, la multiplicidad de bombas "estallando desde el inconsciente de Santiago", la destrucción de "edificios que parecen nichos de cementerios", la "lluvia de cenizas sobre el parque forestal, el cerro San Cristóbal ardiendo íntegro, el río Mapocho de color rojo y la gente huyendo por la oscuridad de las calles", el itinerario por una ciudad donde "llueve ceniza (y) las sirenas aúllan de dolor", configuran un escenario que es interpretado por el narrador-personaje como "un culto (al) Apocalipsis" donde se refuerza la idea de que "El cadáver del siglo XX hiede y una guerra está comenzando (...) mientras el cielo se incendia y las montañas se pudren como el cuerpo de mi tata allá abajo en el suelo del continente" (19). El entorno se signa 
con elementos negativos y formantes que remiten a destrucción y muerte: "Las bandadas de cuervos que cubren el cielo de estos campos de batalla se arremolinan sobre los ojos vacíos de un esqueleto que es consumido día tras día con avidez por la carroña electrónica, carroña porno, carroña de datos revenidos y cabezas de cyborgs ciegos" (143). Ante una representación de mundo donde "la geografía se ha vuelto loca (y) El país se está volviendo loco (...)", el narrador sostiene que "Canales UHF que nadie ve difunden instrucciones histéricas para enfrentar el Apocalipsis" (22).

Otro aspecto relevante donde Lluscuma evidencia características de las narraciones apocalípticas es el constante contrapunto entre diversos períodos de la historia de Chile. Desde la perspectiva de Alejo Steimberg: "La mezcla de épocas es característica de los relatos postapocalípticos contemporáneos (248)". Ello ocurre de manera nítida durante la narración de Lluscuma (la guerra del Pacífico, la pacificación de la Araucanía, las rebeliones indígenas, etc. etc.) donde los diversos hechos permiten apreciar una constante debacle y una violencia constitutiva de la nación. Se sugiere de esta manera que la violencia es, ha sido, y seguirá siendo inevitable en el acontecer histórico futuro del país.

Por último, al igual que lo que sucede en la mayoría de los relatos de ciencia ficción de carácter apocalíptico, en Lluscuma se experimenta una hecatombe nacional en la que los personajes sobreviven en medio de un paisaje destruido, arruinado y sin asomo de un futuro promisorio. Respecto a este punto, James Berger enfatiza que los mundos apocalípticos, en el marco de la ciencia ficción, tienen en común el hecho de que el contexto espacial es siempre una tierra baldía y una distopía urbana ${ }^{11}$. En Lluscuma estas dos dimensiones se hayan presentes y concentran la mirada crítica ante el pasado y el presente del país, situación que hace inimaginable una posibilidad de un futuro abierto para el país: "En el norte se levantaron los obreros del cobre y desde Chuquicamata amenazan con avanzar sobre Santiago con pelotones de

${ }^{11}$ Desde la perspectiva de James Berger: "The apocalypse (...) is The End, or resembles the end, or explains the end. But nearly every apocalyptic text presents the same paradox. The end is never the end (...). In nearly every apocalyptic presentation, something remains after the end (...). In modern science fiction accounts, a world as urban dystopia or desert wasteland 
fantasmas de soldados de la guerra del pacífico y anarquistas fusilados que volvieron de los paredones" (203).

Ligado al tema del dispositivo apocalíptico presente en la representación de mundo, en la novela analizada es posible apreciar una de las consecuencias principales de la experiencia traumática, esto es: el temor inconsciente de que vuelva a suceder aquello que generó en el pasado un dolor profundo y una experiencia de pérdida irreparable. En concordancia con este tipo de sentimiento, Gregorio Kaminsky postula que: "lo que se teme se teme porque es una espera presente de algo que ya aconteció (...). Lo inminente induce a la corrosión de todo presente existente; es el intempestivo presentimiento de estar y no ser, la nada que irrumpe no solo ante o frente sino, lo que se define dentro del propio ser" (48-49). En la novela de Baradit, el evento Lluscuma se percibe justamente como un hecho que puede volver a repetirse: "El tipo lo interrumpió para reconocer que usaban detenidos políticos para aquello grande que se planeaba en Lluscuma para el bien de la patria. Y que iban a intentarlo otra vez con esa misma gente" (128). En el caso de la vidente María Orsic, esta reafirma la idea de una conspiración para que el proyecto sea una posibilidad cierta en tiempo del presente narrativo: "Descubrimos, porque así fue, que ese ejército conspiraría para establecer un contacto abominable con ellos en Lluscuma, un intento que fracasaría, pero que volverían a intentar con éxito probable en 2013" (168).

Esta percepción de que lo terrible retorna siempre se refuerza con la descripción de lo que está ocurriendo en la ciudad de Santiago, que hace recordar lo sucedido el 11 de septiembre de 1973: "Entremedio, un decreto supremo autoriza la intervención militar en el control de la seguridad. Después de tantos años Santiago nuevamente amanece bajo estado de sitio. Aplauso general como siempre" (125). Y poco más adelante: "Por la ventana vemos pasar los Hawker Hunter que aún no reciben el mensaje de volver a Cerrillo y siguen aquí arriba esperando instrucciones" (205).

Sin embargo, por otro lado, las constantes reactualizaciones del pasado

survives (...). The study of postapocalypse is a study of what disappears and what remains" (5-7). 
evidencian una concepción de la historia como entidad dinámica que no termina de realizarse y que es siempre susceptible de constantes interpretaciones. El pasado es una presencia activa, que a pesar de las diversas masacres que registra la historia nacional, puede aún otorgarle al presente y al futuro una nueva inspiración y renovadas pautas de acción. Como afirma Manuel Cruz: "El pasado no está ahí, con sus reclamaciones intactas, esperando ser atendidas, sino que es la materia prima de un determinado quehacer histórico, de eso que Paul Ricoeur ha denominado la tarea de la memoria" (35). Puede afirmarse, entonces, que de alguna manera "El pasado no pasa. La violencia tampoco" (Noemi 130) "la literatura de la violencia deviene literatura de la memoria y, como tal, literatura del presente que puede servirnos para descubrir y revelar" (139).

En Lluscuma se remite al pasado para potenciarlo y darle continuidad a lo que no logró consagrarse, pero sigue bullendo, como por ejemplo las aspiraciones de justicia de los movimientos obreros del cobre en el norte de Chile. Importante es la referencia directa a lo que fueron los ideales de la generación del 38 y del gobierno de Pedro Aguirre Cerda, que a pesar de no haber desembocado en la situación deseada, sigue posibilitando imaginar otro Chile: "Otro país donde Pedro Aguirre Cerda no muera a los tres años de gobierno" (222) y en el que se pueda: "comenzar todo de nuevo, para hacer las cosas bien, para evitar el desorden en el que estamos, país cadáver que se cae a pedazos" $(222)^{12}$. Este impulso benjaminiano, donde se vuelve posible resucitar, en parte, un tipo de memoria que impida que por segunda vez una experiencia de pasado sea frustrada, es formulado por Jean François Macé, cuando señala que: "Evocar un pasado es referirse a lo que de él subsiste, es rememorar las huellas históricas que siguen siendo importantes para grupos sociales en el presente. Entendidas como impresiones grabadas en la memoria

\footnotetext{
${ }^{12}$ Tomás Moulian considera que las fuerzas del 38 condujeron el proceso de refundación democrática (159-160), planteamiento que coincide con el de Bernardo Subercaseux, quien señala que a partir de los años 30 hubo un imaginario de transformaciones que dominó el proceso de reformas antioligárquicas y que basó su máxima en que "los hombres hacen la historia, propuesta de una historia que es producto de la acción humana libre, consciente y racionalmente orientada" (242).
} 
permiten dar una textura histórica a lo que ha desaparecido o ha sido destruido, olvidado o silenciado" $(35)^{13}$.

La persistencia de lo que en el pasado no encontró respuesta, pero que como imaginario continúa demostrando su vigencia, puede apreciarse en los momentos finales de Lluscuma y justamente con relación al tema más sensible de la novela, esto es, el caso de los detenidos desaparecidos. Cabe destacar que, al igual que lo que ocurre con la alusión a la generación del 38, dicha referencia se sitúa al interior de un discurso en clave de delirio subjetivo, donde lo que el narrador dice ver puede ser una proyección de su mente. Sin embargo, ello no devalúa, en lo sustancial, el hecho de que a partir de la conciencia de narrador-personaje se realice una proyección donde, en medio de un entorno apocalíptico y terminal, en el que Santiago no es más que un "agujero humeante" (253), aparezcan los detenidos desaparecidos de tiempos de la dictadura. Dicha epifanía es concordante con el hecho de que: "Todas las cosas vuelven, los problemas no resueltos, eso que hiciste en tu adolescencia, la venganza que nunca llevaste a cabo (...) los huesos que acarrea tu familia, los muertos en sacos de arpillera" (253-254). Es el momento donde el retorno de lo reprimido podrá canalizarse en una posibilidad de saneamiento colectivo, para lograr superar, en parte, la tendencia a "el olvido y los huesos no encontrados que crean tumores en la familia" (254):

Desde el fondo de la Alameda vienen caminando ellos, los que fueron arrebatados a los brazos de sus familias, no entiendo por qué, pero vienen todos ellos, los que estaban desparecidos vienen. Y vienen todos, no falta ninguno. Miran extrañados en todas direcciones, sonriendo nerviosos, con sus ropas de siempre, los lentes en su lugar, las carnes limpias de heridas y perfectos, tal como estaban antes de ser robados y desvanecidos (254).

A modo de conclusión, son pertinentes en este momento las reflexiones del filósofo chileno Sergio Rojas, donde postula que la dictadura chilena

\footnotetext{
${ }^{13}$ Debe recordarse que para Benjamin articular el pasado significa constituir una experiencia con este y exige serle fiel más allá de su fin, retomado sus exigencias que quedaron sin respuesta. Es lo que señala Jean-Louis Déotte, cuando afirma que: "Benjamin ha invertido la historiografía: el historiador no tiene como tarea reconstruir el pasado tal como ha sido en sí mismo, como lo quería Ranke, sino que, partiendo del presente, lanzar un puente hacia lo que yace en el pasado y conserva una carga de utopía" (145).
} 
es aquello expresable solamente a partir de la huella que esta deja, lo que implica pensar lo vivido como "experiencia del desaparecimiento, experiencia de la imposibilidad, experiencia de lo interrumpido, experiencia de la detención: experiencia de aquello de lo cual no existe experiencia alguna" (179). En Lluscuma, bajo la superficie de los acontecimientos, la muerte y la descomposición de los cuerpos de las víctimas exhiben el olor de la culpa colectiva y la urgencia de una justicia más abarcadora que permita que el duelo continúe activo:

\begin{abstract}
No sé si lo estamos sembrando o enterrando como a otro hueso de esos que abundan bajo la alfombra de nuestra memoria. Porque enterrándolo estamos como al parecer lo hacemos con nuestro propio país enfermo, que hoy se desgrana de norte a sur, se derrumba polvo al polvo, tan parecido a este cajón largo y estrecho, mi territorio que se hunde de a poco en la tierra al son de marchas militares y sepultureros de cuello y corbata (12).
\end{abstract}

Se aspira a una forma de duelo que también reconozca la vulnerabilidad de todo sujeto ante la violencia, aspecto que, según Judith Butler, es necesario para lograr un auténtico reconocimiento del semejante, invocar un devenir deseable, y "exigir un futuro siempre en relación con el Otro" (72). La novela de Baradit se erige como un reclamo ante la parsimonia y lentitud con que ha actuado la justicia en el Chile democrático, olvidando que "justicia y memoria son indisolubles, porque sin memoria de la injusticia no hay justicia posible" (Matte 168). Lo que promueve Lluscuma es justamente que el olvido de lo ocurrido en el pasado sería lo peor que podría sucederle al país y con ese fin se tensa la escritura hasta casi exceder las posibilidades de la imaginación. La novela estimula lo que Dominick LaCapra define como el imperativo de realizar con la memoria un trabajo crítico, "con el propósito de renovar posibilidades imaginativas y reabrir las interrogantes del futuro - una necesidad que lleva al arte a una relación particularmente cercana, provocativa y mutuamente cuestionadora de la historia". La memoria deseable para LaCapra es aquella:

que exige el tipo de trabajo de la memoria que Freud relacionaba con la elaboración del pasado. En este sentido, la memoria existe no sólo en tiempo pasado sino también en presente y futuro. Relaciona el conocimiento y la crítica inmanente con la trascendencia situacional del pasado que no es total pero que resulta esencial para 
la apertura a posibilidades más deseables en el futuro" $(29)^{14}$.

Es importante resaltar que las políticas gubernamentales en Chile han evidenciado, desde la publicación de los informes Rettig y Valech un relato un tanto domesticado de la memoria, donde "se ha privilegiado un discurso técnico y legal que silencia otras narrativas locales y periféricas" (Medina 23), debilitadas por lo que Fernando Blanco nomina como una "saturación narrativa de retóricas conmemorativas" Se entiende por ello una amplia tesitura de hechos que abarcan emisiones en TV y prensa de una serie de documentales y noticias que re-editaban el Golpe, determinados productos críticos de la academia, algunos libros dedicados al tema, novelas y testimonios en serie, etc. Según Blanco, el concepto de saturación de retóricas conmemorativas remite especialmente a la pérdida de sentido del evento trágico y su reemplazo por el exceso informativo (32).

Considerando esto y con las reservas del caso, puede proponerse que el género de la ciencia ficción, especialmente como lo entiende y desarrolla Jaime Baradit, actúa como el reverso del impulso domesticador de la memoria y a la vez ofrece nuevos derroteros interpretativos del pasado. Lluscuma de esta manera se integra a una tendencia de la narrativa chilena actual donde sigue siendo imprescindible continuar realizando un trabajo de memoria activo, desarrollar un proceso de duelo sostenido y denunciar los pactos de silencio que todavía existen en torno a los detenidos desaparecidos de la dictadura.

\footnotetext{
${ }^{14}$ LaCapra coincide y apoya la crítica que realiza Charles Maier a la sobreexplotación de un tipo de memoria políticamente distractiva y autoexculpatoria: "El hartazgo de memoria es un signo no de confianza histórica sino de retirada de las políticas transformadoras. Da cuenta de la pérdida de una orientación hacia el futuro, de un progreso en dirección a una mejor ciudadanía o a una equidad creciente" (Maier150). LaCapra, al referirse a los planteamientos de Maier, afirma que "En realidad, la memoria que lo molesta es aquella que se acepta con una "melancolía agridulce". Es la sobredosis de la magdalena cubierta de chocolate de la psiquis. La memoria en este sentido fenomenológico brinda presuntamente un acceso directo a la experiencia, a menudo vicaria, que puede resultar sacralizada o incluso dotada de un aura especial, sobre todo la experiencia traumática de la victimización. Así construida, la memoria implica una fijación con el pasado que inhibe en el presente las acciones que estén orientadas a un futuro más deseable" (27).
} 


\section{Referencias}

Areco, M. "Visión del porvenir y espejo del presente: una panorámica del casi siglo y medio de ciencia ficción en Chile". Cartografía de la novela chilena reciente. Santiago: CEIBO ediciones, 2015.

Baradit, J. Lluscuma. Santiago: Ediciones B Chile S.A., 2013.

Blanco, F. Desmemoria y perversión: privatizar lo público, mediatizar lo íntimo, administrar lo privado. Santiago: Cuarto Propio, 2010.

Barr-Melej, P. Reforming Chile. Cultural politics, nationalism, and the rise of the middle class. Estados Unidos: The University of North Carolina Press, 2001.

Berger, J. After the end. Minneapolis: University of Minnesota Press, 1999.

Brunner, J. J. Cinco estudios sobre cultura y sociedad. Santiago: FLACSO, 1989.

Butler, J. Vida precaria. El poder del duelo y la violencia. Buenos Aires: Paidós, 2006.

Córdoba, A. ¿Extranjero en tierra extraña? El género de la ciencia ficción en América Latina, Sevilla: Ediciones Universidad de Sevilla, 2011.

Correa, S. et al. Historia del siglo XX chileno. Balance paradojal. Santiago: Editorial Sudamericana, 2001.

Cruz, M.: Adiós, historia, adiós. El abandono del pasado en el mundo actual. Buenos Aires: Fondo de Cultura Económica, 2014. 
Deótte, J. La ciudad porosa. Walter Benjamín y la arquitectura. Santiago: metales pesados, 2013.

Fabry, G. e Ilse L. "Los imaginarios narrativos en la literatura hispanoamericana contemporánea (s. XX-XXI)". Los imaginarios narrativos en la literatura hispanoamericana contemporánea. Genevieve Fabry, Ilse Logie y Pablo Decock (eds.). Bern: Peter Lang AG, International Academic Publishers, 2010.

Franco, J. Una modernidad cruel. México: Fondo de Cultura Económica, 2013.

García, A. "Por un análisis político de la desaparición-forzada". Políticas y estéticas de la memoria. Ed. Nelly Richard, Santiago: Cuarto Propio, 2000 .

Jameson, F. "Progress Versus Utopia; or, Can We Imagine the Future?" Science Fiction Studies 9, 1982: 147-158.

Jitrik, N. Producción literaria y comunicación social. Buenos Aires: Sudamericana, 1975.

Kaminsky, G. Escrituras interferidas, Buenos Aires, Paidós, 2000.

LaCapra, D. Historia y memoria después de Auschwitz. Buenos Aires: Prometeo, 2009.

Lem, S. Microworlds: Writing on Science Ficction and Fantasy. Ed. Franz Rottensteiner. San Diego: Harcourt Brace Jovanovich, 1984. 
Macé, J. F. "Marcas históricas y regímenes de visibilidad. De la memoria del terror y de la desaparición. Reflexiones en torno a tres lugares de Chile". Narrativas del terror y la desaparición en América Latina. Buenos Aires. Universidad Nacional de Tres de Febrero, 2016.

Maier, C. "A Surfeit of Memory? Reflections on History, Melancholy and Denial”, History and Memory: Studies in Representation of the Past, 5.2. Otoño/invierno, 1993, pp. 136-152.

Mate, R. La herencia del olvido. Madrid: Errata Naturae, 2011.

Medina, G. A partir del trauma. Santiago: Editorial Cuarto Propio, 2012.

Merril, J. "What do you mean? Science? Fiction?. Thomas D. Clareson ed. S $\mathrm{F}$ The other side of the realism. Essays of modern fantasy and science fiction. Ohio: Bowling Green University Popular Press, 1971, 53-95.

Moulian, T. "Dictaduras hegemonizantes y alternativas populares". Autoritarismo y alternativas populares en América Latina. Material de difusión, Santiago: FLACSO 22, 1981.

Noemi, D. En tiempo fugitivo Narrativas latinoamericanas contemporáneas. Santiago: Ediciones Universidad Alberto Hurtado, 2016.

Pabón, C. "De la memoria: ética, estética y autoridad". Literatura y violencia en la narrativa latinoamericana reciente. Basil, Teresa Coordinadora. Documento disponible para consulta y descargas en Memoria Académica, repositorio institucional de la Facultad de Humanidades y Ciencias Sociales de la Educación de la Universidad Nacional de la Plata, 2015. 
Richard, N. Fracturas de la memoria. México: Siglo XXI Editores, 2007.

Rojas, S. "Cuerpo, lenguaje y desaparición". Políticas y estéticas de la memoria. Ed. Nelly Richard, Santiago: Cuarto Propio, 2000.

Sánchez, C. Novela y cine de ciencia ficción española contemporánea. Una reflexión sobre la humanidad. Lewiston, New York: Ed. Edwin Meller, 2009.

Sontag, S. "The imagination of disaster". (Mark Rose: ed.) Science fiction A collection of critical essays. Englewood Cliffs. N.J. Prentice Hall, 1966, pp. 116-131.

Steimberg, A. "El postapocalipsis rioplatense de Marcelo Cohen. Una lectura de Donde yo no estaba". Los imaginarios narrativos en la literatura hispanoamericana contemporánea. Genevieve Fabry, Ilse Logie y Pablo Decock (eds.) Bern: Peter Lang AG, International Academic Publishers, 2010.

Suvin, D. Metamorfosis de la ciencia ficción. México: F.C.E. 1984.

Subercaseux, B. Historia de las ideas y de la cultura en Chile. Nacionalismo y cultura. Tomo II. Santiago: Universitaria, 2011.

Todorov, T. Introducción a la literatura fantástica. Buenos Aires: Editorial Tiempo Contemporáneo, 1972.

Trujillo, G. La ciencia ficción. Literatura y conocimiento y literatura. México: Instituto de Cultura de Baja California, 1990. 